\title{
LAS MADERAS DE INDIAS
}

\section{Gaspar de Aranda y Antón}

\section{Bosques y aprovechamientos forestales}

El descubrimiento de las Indias por el Almirante Colón en el año 1492 al servicio de la corona de Castilla, puso a disposición de los Reyes Católicos y de sus sucesores en el trono de España unos territorios tan extensos y variados que tardaron muchas décadas los conquistadores castellanos en apreciar su inmensidad y diversidad. El bosque tropical, el manglar, las selvas equinocciales, el estepario altiplano se presentaron a los españoles en el esplendor de su primitiva belleza, que ya el gran Almirante se asombra al bordear las costas de la gran Cubanacan (1).

La diversidad biológica de la pluriselva tropical (2) fue una fuente inagotable de curiosidad científica a lo largo de todo el siglo XVIII. La fragilidad de los ecosistemas tropicales unida al aprovechamiento o mejor a la explotación desordenada de los bosques y selvas a lo largo de la conquista y poblamiento, redujo de muy diversa forma su superficie con mermas cuantitativas y cualitativas de aquellas especies arbóreas (3) de mayor interés económico.

Las Leyes de Indias, desde su desarrollo inicial, contemplaron la riqueza forestal en el uso y disfrute del conquistador y del indígena como lo muestran los «Cortes del Rey» en la Isla Juana (Cuba), así como las Ordenanzas para los bosques de la Habana (1620). La Marina Real tomó bajo su dirección los bosques y montes indianos, principalmente los antillanos, en aplicación de las Ordenanzas de Marina de 1748. De esa manera y durante el siglo XVIII la Marina Real controlaba los bosques situados en la 
costa norte de la isla de Cuba a lo largo de 33 kilómetros, hasta una extensión de 220 kilómetros contados desde La Habana (4).

El bosque cubano fue el mudo rehén disputado por los propietarios de los ingenios azucareros representados en el Real Consulado y la intendencia de Marina representada en la Junta de Maderas.

Unos y otros, los industriales azucareros y los astilleros y arsenales de La Habana y Real Sitio de la Tenaza, abatieron cedros, guayacanes, caobos y pinos, para su uso como fuente de energía y para la construcción civil y naval.

El bosque tropical de frondas impenetrables y monzónico, de vegetación perennifolia siempre verde, y el también bosque de coníferas caían talados bajo el hacha de un progreso y una nueva cultura y tecnología. Las maderas de roble, de ácauca, quiebrahacha, capá y ceiba fueron destinadas a los arsenales americanos para dar origen a una gran flota ultramarina. El granadillo, catey, palonazareno, dieron lugar a hermosos muebles que adornaron los palacios de virreyes y capitanes generales.

Los industriales azucareros talaron los bosques en busca de combustible para sus ingenios y roturaron tierras y efectuaron rompimientos a costa de los territorios forestales, para así extender la superficie de las plantaciones de caña.

Por su parte, la Marina se proveyó de maderas suficientes para construir en el período que va de 1734 a 1781 sesenta y siete navíos de línea.

En el año 1789 se promulgó la Real Cédula de once de diciembre sobre el uso de maderas en la plaza de Cuba, y en 1803 la creación en la isla de los astilleros de Mariel, Matanzas, Jagua y Nipe. Años más tarde, en 1812, se libera a los propietarios de los montes, mediante la Real Cédula de Montes y Plantíos, del yugo de la jurisdicción de la Marina. Por último en el año 1815 quedan derogados en América los privilegios sobre los montes que tenía la Marina Real.

La gran riqueza de los montes ultramarinos en maderas, por entonces de un gran valor estratégico, dio lugar a que las autoridades españolas dictaran una serie de normas que regulaban la extracción de las mismas a partir del siglo XVI (5).

La riqueza forestal de la Isla de Cuba era proverbial y así hablan de ella Herrera en sus Décadas y el Padre Las Casas (6), y sus maderas preciosas de teca y caoba fueron llevadas en navíos con destino a la construcción de El Escorial y del Palacio Real de Madrid.

Para el suministro de maderas al Real Astillero de La Habana se establecieron los ya mencionados Cortes del Rey (7). 
Durante el siglo XVIII, y como hay constancia en el Archivo General de Simancas (A.S.), tanto en los legajos correspondientes a Secretaria de Marina como de Hacienda, se dictan disposiciones sobre la manera y forma de establecer las cortas y clases de madera y cantidades necesarias para la fabricación de bajeles, así como de noticias de envíos de maderas a la península (8).

Las visitas de los subdelegados de Marina fueron práctica continuada para valorar la riqueza maderera de los bosques americanos, con el fin de abastecer a los arsenales y astilleros tanto indianos como peninsulares (9).

Toda esa aplicación de maderas a la tecnología de la arquitectura naval hizo necesario que se desarrollara una incipiente selvicultura, con criterios tecnológicos de máximo rendimiento dentro de la gestión de las masas forestales explotadas, en la que quedaron por las Ordenanzas más perfectamente determinados los criterios de selección en la corta, buscando en el árbol en pie la pieza o ligazón más conveniente para el uso naval, en razón del diseño del navío según su porte. Esta clase de selección de tipo dendromórfico pie a pie es de una forma particular de entresaca no regularizada de corte atípico (10). La falta de una planificación en la gestión del bosque, unida a la carencia de una técnica apropiada en la corta y transporte de la madera a los centros de consumo, incrementada por el desconocimiento del comportamiento de las mismas, originó elevadas pérdidas de producto.

Fueron varios los métodos empleados por los agricultores en las cortas de maderas, dentro del sistema de aprovechamientos, como el método de "a tumba y deja» en que mediante una previa limpieza de maleza en la zona de la corta se talaban los árboles con destino en general para combustible, y el método «a tumba y limpia» en que con maleza y con los árboles se hacía una gigantesca hoguera quedando el suelo listo para efectuar una plantación agrícola (11).

Los bosques y selvas filipinas dependientes administrativamente del virreinato de Nueva España fueron regulados desde la conquista hasta muy entrados en el siglo. XIX por las Leyes de Indias (Ley 14, título 17, libro 4 de 1594), sobre los derechos del indígena a cortar madera para su uso en los montes de la Corona. Posteriormente, una Real Orden de 1797 limitó esos derechos a los terrenos unidos o inmediatos a los pueblos.

Los marinos Jorge Juan y Antonio de Ulloa (12) nos hablan de las excelencias de las maderas de los montes de Guayaquil y de los bosques situados entre Chiloé y Acapulco, haciendo descripciones sobre las cualidades de distintas maderas como el guachapeli, roble amarillo, maría, 
canelo, manglé, bálsamo y laurel en su aplicación a la construcción de buques.

Otros autores como Nicolás Monardes en su Primera, Segunda y Tercera partes de la Historia Medicinal de las cosas que se traen de nuestras Indias Occidentales que sirven en medicina (1565) nos hacen descripciones de las excelencias de la jalapa, sasafrás y la cebadilla, de las nuevas propiedades del tabaco, canela, guayacán y de los árboles del bálsamo y otras propiedades del maíz, piña, cacahuete, batata, zarzaparrilla y ricino. Respecto de la madera de guayacán (Guayacum officcinale), Francisco Delicado (1529), clérigo de Martos (Córdoba), publica El modo de apoderarse el legno de India Occidentale que describe la forma de preparar con madera de guayacán el leño de Indias, un remedio útil en el tratamiento de la sífilis.

Ruiz Díaz de la Isla (1539) en un Tratado sobre el fruto de Todos los Santos contra el mal serpentino venido de la Isla Española reconoce las propiedades curativas del guayacán, alegando la procedencia americana de la sífilis. La decocción de la raspadura de la madera del guayacán seguirá utilizándose hasta muy entrado el siglo XVIII, apreciándose en ella propiedades de tónico-amargo, diurético y sudorífero eficaz.

Plantas como el palo de campeche (13) y el añil, también salieron de los bosques y selvas de América.

\section{La construcción naval en las Indias}

El mayor y más importante astillero de América, e incluso de todo el imperio español, durante la primera mitad del siglo XVIII fue el Real Arsenal y Astillero de La Habana en la isla de Cuba. Este astillero fue fundado en el año 1725 cuando España controlaba solo el 5\% del comercio de América.

Las naves construidas en La Habana tuvieron siempre fama de extraordinaria calidad. Entre 1734 y 1781 se construyeron nada menos que 67 grandes navíos de línea. Cuando el Marqués de la Ensenada planeó dotar a la armada real con 15 nuevas unidades, los 10 barcos de mayor tonelaje fueron construidos en La Habana y únicamente en El Ferrol las 5 embarcaciones menores (14).

Ya en el año 1717 existía el proyecto de creación de un astillero en la Gran Antilla para construir, apostar la flota, reparar y carenar buques. Su 
fundación fue a iniciativa de J. Campillo. Siguiendo el método Gaztañeta se construyeron muchos buques entre 1726-1739 mediante asientos con la Compañía de La Habana, continuando la construcción durante los años 1741-1749. La actividad siguió hasta el año 1750 (15).

Diez años más tarde de la fundación del Astillero de La Habana, en el 1735 fue creado el Real Astillero del Sitio de la Tenaza también en la isla de Cuba, siendo remodelado en 1739 según el Plan de Ampliación y Modernización de la Armada a impulso del Marqués de la Ensenada. Se crea para ello ex-profeso un asiento con la Marina y la Real Compañía de Comercio de San Cristobal de La Habana, por lo que en el período que va de 1741-1749 se contrató la fabricación de 10 navíos de línea.

Se abastecía de maderas el astillero de la Tenaza de la zona de Chihuaua, Matanzas, Camarioca, Sagua y Bahía Honda. Entre 1760-1794 se botaron en él 7 navíos de la serie de 12 de 70 cañones.

Otro importante astillero americano fue el de Guayaquil, en el cual en el año 1752 se efectuó la construcción del navío San José El Peruano, que resultó un fracaso completo por utilizar un diseño inconveniente.

Años más tarde, el rey D. Carlos III, en 1768, relanzó el astillero y para ello en el año 1783 se solicitó al gobernador de la región que recogiese muestras de distintos géneros de maderas (16) que se producían en dicha jurisdicción.

En el año 1790 el navío Santiago El Fuerte partía para la península con 24 trozos de cada una de las maderas seleccionadas: guayacán, negra, caña, fístola, tinto, algarrobo, mangle caballero, mangle colorado, canelo, matasarna, cacol, coquito, amarillo y colorado, para que los técnicos y carpinteros de los astilleros experimentaran y conocieran las excelencias de las maderas guayaquilenses.

En las inmediaciones de Guayaquil se llegaron a contar 30.000 árboles de edad y tamaño capaces para servir en la construcción de navíos de 70 cañones. Para este tipo de embarcaciones de alto porte se seleccionaron las maderas de roble, canelo, guachapeli, moral, caña, fístola, amarillo, colorado y bálsamo (17).

Otro astillero fue el de Realejo, en el golfo de Fonseca, aprovechando la bondad de las maderas de sus alrededores para su empleo y uso en la arquitectura naval (18).

El Real Astillero de Coatzacoalcos tuvo una efímera vida de quince años (19) y lo poco que allí se construyó resultó a unos costos muy elevados. 
La construcción de un navío en el astillero se describe así:

Se comienza con el armazón del casco, formándose para ello una empalizada de postes fuertemente clavados en el suelo; sobre una base de tablones se coloca la QUILLA y se levanta el codaste, el pie de roda y la roda, a continuación se colocan las cuadernas, baos, etc. dando forma estructural al navío. Poco a poco y a medida que son visibles las líneas del casco y que se sube hacia arriba es necesario montar poleas y polipastos para la elevación de los materiales.

El mástil (palo mayor), así como el trinquete, mesana y bauprés, como los palos de gavias, se mueven y se preparan con ayuda de un molinete.

El tablazón para el casco y puentes se prepara sobre grandes «borriquetas".

La mecha cuadrada o rectangular del palo encaja en la carlinga sobre la quilla.

Una vez terminada la estructura y puestos los forros se bota el navío y se le tumba de quilla, es decir acostado sobre una banda para que la mitad del casco por debajo de la línea de flotación quede al descubierto. Un equipo de operarios se ocupa de calafatear los tablones y juntas mediante una mezcla de alquitrán y estopa que después se flamea para que se adhiera fuertemente a la madera, y así conseguir una protección de la misma y el casco pueda conservarse contra las tarazas, moluscos y broma. Mientras las bombas, con su largos canalones, achican el agua del navío (20).

Esta sencilla descripción muestras las tareas más significativas que se precisaban para botar una embarcación.

De Sta. María de Chimilapa se hicieron talas ingentes de árboles para el suministro de arboladuras a los astilleros de las costas antillanas (21).

Desde el diseño Gastañeta al de Jorge Juan, llamado el «método inglés», pasando por el Gautier, y Romero Fernández de Landa todos tuvieron su aplicación en el astillero de La Habana y navío como el Santísima Trinidad salió de sus diques (22).

Felipe II mandó que se pusiera en servicio el astillero de Bahía de los Sacrificios, en Veracruz del virreinato de Nueva España, pero el Marqués de la Ensenada lo suprimió en el año 1747.

Durante los siglos XVI y XVII gran parte de las embarcaciones de la flota mercante española fue construida en los astilleros de las Indias. 
Un ejemplo de ello es que de los 239 buques utilizados en los viajes de las Flotas de Indias en el período comprendido entre 1669 y 1700, 47 embarcaciones, es decir, una quinta parte, fueron construidas en los astilleros criollos. Por entonces, los astilleros y arsenales de La Habana, Guayaquil y Cavite eran famosos (23).

Del astillero de La Habana salió en 1723 el navío de 2 puentes y 80 cañones denominado "Rayo», que más tarde se transformó en uno de 3 puentes y 100 cañones y que fue hundido por los ingleses en 1762. En el período comprendido entre 1786 a 1794 fueron construidos el «Mexicano", "Salvador del Mundo», «Real Carlos», "San Hermenegildo» y "Príncipe de Asturias» de 3 puentes y 112 cañones.

Es de resaltar por su larga duración el navío "San Carlos», de diseño Jorge Juan construido en La Habana en 1765 de 2 puentes y 80 cañones, y carenado en 1801 en Cartagena siendo transformado en un buque de 3 puentes y 112 cañones.

Del sistema de Romero Fernández de Landa (1782), sin duda el diseño más conseguido de navío español de línea del siglo XVIII, salieron de La Habana, el «Mejicano» (1786), el "Real Carlos»(1787), el "San Hermenegildo» (1789) y el «Príncipe de Asturias» (1794).

En el año 1765 se botaron en La Habana 3 navíos de 98 cañones.

En el estado naval de 1774, en los apostaderos ultramarinos había las siguientes unidades de la marina de guerra:

\begin{tabular}{lccccc}
\hline & Navios & Fragatas & Corbetas & Otros & Total \\
\hline La Habana & - & 4 & - & 18 & 22 \\
Cartagena de Indias & - & 2 & - & 2 & 4 \\
Veracruz & 3 & - & - & 2 & 5 \\
El Callao & 2 & 3 & - & 1 & 6 \\
Puerto-Rico & - & - & - & 1 & 1 \\
Buenos Aires-El Plata & - & 3 & 2 & - & 5 \\
Cucumá & - & - & - & 2 & 2 \\
Filipinas (Cavite) & - & 2 & 2 & 10 & 14 \\
\hline & 5 & 14 & 4 & 36 & 59 \\
\hline
\end{tabular}


de un total de 143 buques incluida la reserva naval (de ellos 58 navíos de línea, es decir, más de 50 cañones). Muy superior al estado naval de 1766:

\begin{tabular}{lccccc}
\hline & Navios & Fragatas & Corbetas & Otros & Total \\
\hline Cartagena de Indias & - & 2 & - & 3 & 5 \\
Veracruz & 3 & - & - & 2 & 5 \\
El Callao & 2 & 3 & - & 3 & 8 \\
Puerto-Rico & - & - & - & 1 & 1 \\
Buenos Aires-El Plata & - & 3 & 3 & 2 & 8 \\
Cucumá & - & - & - & 2 & 2 \\
Filipinas (Cavite) & - & 2 & - & 15 & 17 \\
\hline & 5 & 10 & 3 & 28 & 46 \\
\hline
\end{tabular}

de un total de 132 buques incluida la reserva naval (de ellos 59 navíos de línea, es decir, más de 50 cañones).

En esa mitad del S. XVIII la flota de guerra destinada en las Indias supuso de un $30 \%-40 \%$ del total de los efectivos, aunque en navíos de gran porte el porcentaje era mucho menor, cifrándose en un orden del $3 \%$ al $4 \%$.

Gran parte de la flota del siglo XVIII, que ocupaba en el ranking mundial la $3^{a}$ plaza, muy pareja a la francesa y alejada de la inglesa, había sido construida en los astilleros americanos, con maderas americanas y con tecnología europea. Una gran empresa pública se creó en América para llevar a cabo tan importante tarea como fue la construcción naval en las Indias, sobre todo en el siglo XVIII y en los astilleros caribeños principalmente.

\section{Tecnología Naval de las Maderas}

Las maderas de los bosques de las Indias, dada las inmejorables características técnicas que determinadas especies tenían para su uso en la arquitectura naval durante los siglos XVI al XIX, fueron motivo de búsqueda y valoración por la Corona Española. 
Jorge Juan y Antonio de Ulloa, en su manuscrito Noticias Secretas de América (24) nos hablan de las excelencias y calidades de las maderas de los bosques de Guayaquil y de la abundancia de las mismas. De ambos marinos recibimos esta información: «...hay maderas, cuya abundancia y calidades no se encuentran, no solo en ningún otro país de la nación española, ni de los dependientes de otros monarcas...»; continúan diciendo: «... es tanta la abundancia de las maderas, que la mayor parte del país, que corresponde a la Jurisdicción de Guayaquil, se compone de espesos bosques donde el mayor costo es el que ocasiona en pagar los peones que las cortan y desbastan para bajarlos a Guayaquil». Al tratar la calidad de las maderas de aquellos bosques describen las principales especies que sirven allí para la construcción de los navíos como: guachapelí, roble amarillo, maría, canelo, mangle, bálsamo y laurel, aclarando que «... todas estas maderas que son distintas entre sí por sus cualidades, se emplean en la fábrica de los navíos, aprovechando cada especie en aquellos fines que para mí más a propósito....”

A continuación describen aquellas maderas de los montes de Guayaquil que presentan las más altas calidades para la construcción de navíos.

"El Guachapeli es la madera mas admirable que se ha descubierto hasta el presente, porque es muy sólida y fibrosa con variedad de extensiones; tiene muy pocos nudos, es muy suave al corte, casi incorruptible, y tan xugosa que al tocarla con el hacha después de sesenta o más años de servicio, parece que está acabada de labrar. Esta madera se destina para los planes, piques, estemenaras y demás posturajes, curvas y motonería. Tiene el defecto, aunque corregible, de que toda la parte blanca se pudre con grande facilidad. Su color propio es entre colorado y amarillo, pero inmediato a la corteza suele tener algunos pedazos blancos superficiales, que son aquellas partes que todavía no se han perfeccionado bien; y como esto no profundiza mucho, si se tiene el cuidado de cortarlas al tiempo de labrar la madera, hasta que descubra por todas partes su lexítimo color, no hay peligro de que se corrompa; y los navíos que se fabrican con ella, son de una duración nunca oída en Europa como se experimenta allí; pues dexando aparte los navíos que hay en aquella mar con cincuenta o más años de servicio, todavía alcanzamos uno á quien llaman El Christo viejo, cuyo nombre le habían puesto por ser tal su antigüedad, que se había perdido la memoria del tiempo, y constructor que lo fabricó; siendo así que la hay de los constructores que se han conocido en Guayaquil de ochenta ó más años a esta parte, entre los quales ninguno lo había fabricado, y era anterior á todos. Este navío se perdió al fin, y sin este accidente navegaría todavía, pues después de tantos 
años, tenía todas sus maderas tan sanas como si acabara de salir del astillero (...)

El Roble de Guayaquil no es la misma calidad que el de Europa, pero aunque tiene menos fortaleza que el nuestro, no está dispuesto á rajarse con tanta facilidad, porque siendo muy trabada su fibrazón, y dispuesta en distintos, órdenes, forma un cuerpo bien entretexido por todas partes: además de esto, es dócil para trabajarse, y siendo esta circunstancia tan ventajosa se aplica á la tablazón, la qual dura mucho en los navios: porque sobre sus buenas calidades tiene la de no estar sugeta á la broma, y aunque esta no es comun en las costas de Chile ni del Perú, se halla desde la costa de Panamá acia Acapulco.

El Palo Amarillo, cuyo nombre muestra su color, es madera fuerte, compacta y de mucha duración, y por esto se aplica para palos, latas, durmientes, palmejares, y otras cosas donde se requiere que sea de esta naturaleza.

Las arboladuras se hacen de la madera María, muy diferente de la que se conoce con el mismo nombre en la costa de Cartagena, en la Habana y otras partes de la América acia el Mar del Norte, porque la María de Guayaquil es mucho mas ligera y mas flexible que la de otros paises, aunque no lo es tanto como el pino de Europa, al qual excede en la fortaleza. Es tan propia para arboladuras que no se oyen exemplares de desarbolos en aquella mar, sino los que la ocasión ha hecho necesarios para salvar los navios, siendo así que experimentan temporales de bastante fuerza. Esta es la única de todas las maderas que producen los montes de Guayaquil que reconoce dueño; no porque lexitimamente lo tenga el sitio que la produce, sino porque algunos vecinos de Guayaquil ofrecieron dar una corta suma á la Real Hacienda, con tal de que en nombre de Su Magestad se les concediese el privilegio de ser los únicos que pudiesen cortar arboladuras allí, obligandose asimismo dar al Rey, por el costo del corte y conduccion, la que hubiesen menester los navios de su armada; y por esto todos los dueños particulares de embarcaciones necesitan tomarla de estos sugetos que pueden solamente cortarla, habiendo en lo dilatado de aquellos montes un paraje determinado en donde se crian las Marias, y son mas comunes que en todos los demas.

El Canelo, que es de madera muy dura y pesada, se emplea en quillas para las embarcaciones, y en otras piezas que requieren fortaleza. Tambien se hacen quillas de Mangle, porque siendo madera incorruptible en el agua, concurre en ella, ademas de esta circunstancia, la de haber palos, cuyo largo pasa de cuarenta varas, y gruesos á proporcion.

El Bálsamo, cuya madera es sólida, firme y muy pesada, se emplea en bombas; y del laurel, aunque pesado y poco flexible, se hacen remos, por no haber otra mas adecuada para el intento. 
A las particularidades que se han expresado en abono de estas maderas, se agrega la de que empezando á trabajarlas desde que se acaban de cortar en el monte, y conducirlas al astillero aun estando enteramente verdes, no por esto es de menor duración el barco que se construye con ellas que el que se hiciera con maderas secas y curadas, porque nunca llega el caso de dañarse ó corromperse: circunstancia digna de ser notada.

Pero no solo las maderas son productos que se extraen de los bosques americanos, sino las breas, alquitranes, cañamos, y estopas son tambien sacados de los mismos.

La brea y el alquitran se llevan de la costa de Nueva España, ambos son de buena calidad, y en sus precios no hay fixeza, siguiendo la mayor ó menor abundancia. Se ha dicho que este alquitran quema las xarcias, lo cual sucede con otra especie llamada cope que se saca en la misma jurisdicción de Guayaquil en el partido de la Punta de Santa Elena, y en las cercanías de Amotape, jurisdicción de Piura, del qual se sirven los particulares para su baxo precio, mezclandolo con el bueno, y de este modo no causa tan mal efecto.

La jarcia que hay en el astillero de Guayaquil es la que se fabrica en Chile, donde se cria el cáñamo cuya calidad es superior al del Norte de Europa, excediendole tambien a lo largo, pero aquellas gentes no saben rastrillarlo y limpiarlo bien. Tambien se hace cordaje de pita en la jurisdicción de Guayaquil, del qual solo usan las embarcaciones pequeñas, y las destinadas al tráfico de aquella costa, sin extenderse mas que hasta Panamá.

La estopa que se emplea en todas aquellas embarcaciones es de dos especies; una que es la de coco para las costuras que están debaxo del agua, y la otra que es la regular de cáñamo para las que quedan afuera. La estopa de coco es tan propia para las costuras debaxo del agua, que no reconoce corrupción, y una vez puesta dura tanto como la tablazon: se endurece, y uniendose con las maderas que la comprimen, forma un cuerpo con ellas, y por esta razón todas las carenas que se dan á los navios en aquella mar se reducen á apretar las que se afloxan, limpiar los fondos, reclavar las tablas, y poner algun rumbo quando lo necesitan; de suerte que los clavos fallan, y la madera permanece, no siendo esto de admirar porque se sabe que el agua disuelve el hierro, y que hay muchas maderas cuya naturaleza pide el estar dentro del agua para conservarse exentas de corrupcion. La estopa de coco es de la misma calidad, y así no será facil hallar otra materia tan propia para llenar los vacíos que dexan las tablas y que dura al igual que ellas. Además de la incorruptibilidad de esta estopa debaxo del agua se observa en ella que despues de oprimirse en seco todo quanto es posible, como se hace al tiempo de meterla, luego que se moja se hincha y aprieta tanto en las costuras que no es facil concebirlo. Esta 
misma humedad y la grande opresion en que se halla, la hace unirse mas fuertemente á la madera de las tablas, y que forme con ellas un cuerpo tan sólido, como si no fuera más de uno todo el conjunto. No sucede lo mismo quando se pone esta estopa fuera del agua, secandose, se adelgazan sus fibras, y se afloxa la que está en las costuras, por cuya razon no es adequada para estos parages, y se usa en ellos la de cáñamo que no está sugeta al mismo inconveniente.

Esta estopa se hace de la corteza que tienen los cocos al rededor de si, cubriendolos tan fuertemente que para sacarlos de ella es necesario industria y fuerza. El modo de hacerla es bastante sencillo, pues solo consiste en machacar bien esta cáscara, hasta que las fibras se separen y queden libres de la carnosidad que las une, la qual se separa de forma aserrin. No parece que en los astilleros de la Habana se haya probado hasta el presente esta especie de estopa, pues si lo hubieran hecho se hallarian con ella tan ventajosamente como en la mar del Sur, y no se servirian de otra para los fondos de todas las embarcaciones que se fabrican y carenan en aquel puerto y otros de las costas inmediatas.

No solamente convendria que se estopasen los fondos de todos los navios en la Habana con esta estopa de cocos, sino tambien que en aquel puerto y en todos los demas de las costas de Cartagena y Vera Cruz, á donde suelen ir navios de guerra, y donde hay abundancia de esta fruta (cuya cáscara se desperdicia) se dispusiese, que convertida esta en estopa, se traxese á España en lugar de venir vacíos; con lo cual se excusarian grandes sumas en los arsenales, porque allá costaria muy poco, y acá duraria muchos, sucediendo todo lo contrario con la estopa de cáñamo, pues cuesta mucho y dura poco estando debaxo del agua.

El sebo que se consume en aquel astillero, es el de las rezes que se matan en el mismo país y el que se lleva de Chile. Las lonas que todas son de algodon, se fabrican en Caxamarca, Chachapoyas, y otras provincias de Perú.»

Estas maderas no solo fueron destinadas a uso de la Marina, sino que fueron utilizadas para las fábricas de innumerables casas de El Callao y Lima. Igual empleo tuvieron las maderas procedentes de Chiloé, Valdivia y Concepción, aunque como dicen Jorge Juan y Antonio de Ulloa (25) «... son totalmente diversas a las de Guayaquil y muy sujetas a corrupción, por cuya razón duran muy poco los barcos que se construyen allí, razón esta por lo que no se han fomentado estos astilleros...". No obstante de aquellos bosques hay que resaltar el avellano de Valdivia, de gran flexibilidad, por lo que sin emplear ningún artificio "toman toda la vuelta», el alerce de Chiloé que es bueno para pañoles, mamparas y obras de esa cali- 
dad con el peligro de que se raja con facilidad y se tuerce. En el Astillero de Realejo de Nueva España se construyeron muchos navíos de guerra de madera de cedro, pese a la corta duración de los mismos, ocurriendo lo mismo con los navíos fabricados en el astillero de La Habana con igual madera.

En Chincha, al sur del puerto de El Callao, se fabricaron pequeñas embarcaciones con la madera de espino que presenta características como que es pesada, dura y muy fuerte y cerrada de poros que permite una magnífica sujección a la clavazón.

Hay que hacer resaltar la gran duración de los navíos construidos con maderas americanas, así como su mayor resistencia a la broma (26), hecho este que ocasionó que desde las Indias se enviara mucha madera a España (27).

Esta calidad encontrada en las maderas de los bosques cubanos, peruanos y del istmo hizo que todos los diseños de arquitectura naval fueran aplicados en los astilleros americanos (28) con unos consumos de gran importancia (29).

El reconocimiento mediante expediciones ex-profeso para determinar la riqueza forestal en maderas de los inmensos territorios americanos, lo encontramos en las relaciones inventariales levantadas en Guayaquil, Islas Trinidad, Costa de Paria, Río Orinoco, Guayana, Panamá, Darien del Sur, Chiloé, etc... (30).

La bondad tecnológica de las maderas americanas, unida a la belleza de muchas de ellas, hizo que llegara a ser normal en España durante el siglo XVIII que ciertas piezas de los buques como motonería y timones se construyeran con caobos de Cuba y de La Española así como de sabicú o guayacán, por no hablar de la utilización masiva de las mismas en edificaciones mobiliarias de lujo, caso del Palacio de Oriente de Madrid (1839), levantado sobre las ruinas del incendio del antiguo alcázar de los Austrias en donde se perdieron numerosas obras de arte de la pintura española.

La extracción masiva de madera para la construcción naval se hace en las Indias principalmente en las áreas caribeñas y antillanas (31), sin olvidar otras noticias como que en Valparaíso se conocían las maderas de nogal, ciprés, canelo, roble bellota y laurel y en Coquimbo el sauce y el algarrobo (32).

En Acapulco (Nueva España) se obtenían de sus pinares la brea necesaria para el calafateado de las embarcaciones y en San Blas hay descripciones del cedro, manglé y guayacán para embarcaciones (33). 
Hacia 1515 se intentó la fabricación de embarcaciones de pino y caoba por los padres jerónimos gobernadores de La Española, así como obtener gomas del copey para calafateado de cascos de buques contra el ataque de la broma (Teredo navalis, $L$.).

Estado general de maderas marcadas en las bocas y caños del Orinoco

\begin{tabular}{lrr}
\hline \multicolumn{1}{c}{ Especies } & Arboles & Piezas \\
\hline Mura & 12.338 & 16.012 \\
Cedro & 779 & 1.233 \\
Cazapo & 6.987 & 8.664 \\
Apamate & 163 & 188 \\
Tutumillo & 92 & 93 \\
Angeli & 16 & 16 \\
Algarrobo & 240 & 358 \\
Guaciva & 1.017 & 1.198 \\
Lombricero & 214 & 270 \\
Roble & 600 & 836 \\
Sazafraz & 5.000 & 6.900 \\
Cavimba o azeite & 3.400 & 4.358 \\
Curo & 200 & 422 \\
\hline Total árboles marcados/piezas & 31.046 & 40.548 \\
\hline
\end{tabular}

Fuente: SHM. Catálogo General de Documentos 
Estado general de maderas marcadas en las bocas y caños del Orinoco

\begin{tabular}{|c|c|c|c|c|}
\hline$N .^{\circ}$ & Nombre científico & $\begin{array}{l}\text { Nombre } \\
\text { vulgar }\end{array}$ & Destino & $\begin{array}{c}\text { Distribución } \\
\text { Geografía }\end{array}$ \\
\hline 1 & Swietenia mahogani & caoba & $\begin{array}{l}\text { motonería, } \\
\text { decoración }\end{array}$ & Antillas \\
\hline 2 & $\begin{array}{l}\text { Catalpa, Bignonia, } \\
\text { Tecoma, Citharexylin, } \\
\text { Erectia }\end{array}$ & roble & quillas, codaste & Ecuador, Venezuela \\
\hline 3 & $\begin{array}{l}\text { Cordia alba, } \\
\text { Cordia Gerascanthus }\end{array}$ & capá blanco, prieto & quillas & P. Rico \\
\hline 4 & Nectandra porphyria & laurel & tablazón & Cuba, Venezuela \\
\hline 5 & Podocarpus coriaceus & sabina & tablazón & Cuba, Sto. Domingo \\
\hline 6 & (varias especies) & pinos & arboladura & Cuba, Norteamérica \\
\hline 7 & Bombax ceiba & ceiba & $\begin{array}{l}\text { canoas, } \\
\text { embarcaciones } \\
\text { menores }\end{array}$ & Cuba \\
\hline 8 & Achras mammosa & mamey & carrozas, yemos & Cuba \\
\hline 9 & Tectonia grandis & teca & $\begin{array}{l}\text { quillas, cuadernas } \\
\text { palmajares }\end{array}$ & Filipinas \\
\hline 10 & $\begin{array}{l}\text { Guayacum officinales } \\
\text { G. Sactus }\end{array}$ & guayacán & rondanas & $\begin{array}{l}\text { Antillas, Colombia, } \\
\text { Chile, Ecuador }\end{array}$ \\
\hline 11 & Cedrela adorata & cedro rojo & & Colombia, Antillas \\
\hline 12 & Araucaria imbricata & araucaria & tablazón & Argentina, Brasil \\
\hline 13 & $\begin{array}{l}\text { Comodalia, } \\
\text { Chicharronia, Terminalia }\end{array}$ & chicharrón & codastes, rodas & Cuba, Sto. Domingo \\
\hline 14 & $\begin{array}{l}\text { Ancennia, Rhizophora, } \\
\text { Leguncularia, } \\
\text { Odontandra, Conocarpv }\end{array}$ & $\begin{array}{l}\text { manglé } \\
\text { us }\end{array}$ & tablazones & Antillas \\
\hline 15 & (ver Palo María) & ocuje & arboladuras & Cuba, Sto. Domingo \\
\hline 16 & (Moca o pangelin) & yabá & $\begin{array}{l}\text { carros de artillería } \\
\text { y cureñas }\end{array}$ & Cuba, Sto. Domingo \\
\hline 17 & $\begin{array}{l}\text { Callophyllum } \\
\text { Inophyllum }\end{array}$ & palo-maría & arboladuras & Ecuador \\
\hline 18 & Acer sacharinum & arce azucarero & quillas & Ecuador \\
\hline 19 & Pinus mitis & pino de Canadá & arboladuras & Canadá \\
\hline 20 & Pinus australis & pino de la Florida & $\begin{array}{l}\text { arboladuras, } \\
\text { tablazón }\end{array}$ & Norteamérica \\
\hline
\end{tabular}




\section{(Continuación)}

\begin{tabular}{|c|c|c|c|c|}
\hline$N .^{\circ}$ & Nombre científico & $\begin{array}{l}\text { Nombre } \\
\text { vulgar }\end{array}$ & Destino & $\begin{array}{l}\text { Distribución } \\
\text { Geografía }\end{array}$ \\
\hline 21 & Q. virens & roble de Virginia & $\begin{array}{l}\text { quillas, cuadernas } \\
\text { codastes }\end{array}$ & Norteamérica \\
\hline 22 & Pinus strobus & $\begin{array}{l}\text { pino de } \\
\text { Lord Weymouth }\end{array}$ & arboladuras & Norteamérica \\
\hline 23 & Dimorphandra Excelsa & mora & $\begin{array}{l}\text { busardas, timones, } \\
\text { tamajares, curvas } \\
\text { y baos }\end{array}$ & $\begin{array}{l}\text { Venezuela, } \\
\text { Sto. Domingo, : } \\
\text { Guayanas, P. Rico }\end{array}$ \\
\hline 24 & Bignomia leucoxylon & cedro blanco & $\begin{array}{l}\text { Busardas, baos, } \\
\text { ligazones, tablazón }\end{array}$ & C. Rica, Jamaica \\
\hline 25 & Anderoba & carapo & $\begin{array}{l}\text { Busardas, baos, } \\
\text { ligazones, curvas }\end{array}$ & Venezuela \\
\hline 26 & Tecoma pentahylla & apamate & tozas, vitas, curvas & Colombia, Venezuela \\
\hline 27 & Totuma & tutumillo & avitores, curvas & América meridional \\
\hline 28 & Dicorynia paramensis & angeli & $\begin{array}{l}\text { quillas, rodas, } \\
\text { codastes, ligazones, } \\
\text { baos }\end{array}$ & Guayana \\
\hline 29 & $\begin{array}{l}\text { Humenaza curbaril, } \\
\text { Pithecolobina saman }\end{array}$ & algarrobo & hosquillas curvas & Cuba, Ecuador \\
\hline 30 & Guasima & guaciva & $\begin{array}{l}\text { quillas, rodas, } \\
\text { codastes, ligazones, } \\
\text { baos }\end{array}$ & Antillas \\
\hline 31 & Copaiba hemitophylla & cabimba & $\begin{array}{l}\text { ligazones, baos, } \\
\text { curvas }\end{array}$ & Venezuela \\
\hline 32 & Hulefandia pendula & cedro macho & $\begin{array}{l}\text { ligazones, baos, } \\
\text { curvas }\end{array}$ & P. Rico \\
\hline 33 & Guayacum verticale & guayacancillo & tablazón & Cuba, P. Rico \\
\hline 34 & Acacia guachapela & guachapeli & tablazón & C. Rica, Ecuador \\
\hline 35 & Calophyllum calaba & maría & ligazones, tablazón & Antillas, Colombia \\
\hline 36 & Benreria secculenta & roble guayo & tablazón & Cuba, P. Rico \\
\hline 37 & $\begin{array}{l}\text { (ver Guayacam o } \\
\text { cedro blanco) }\end{array}$ & guayaco & rondanas & Antillas, Colombia \\
\hline
\end{tabular}

(Consulta: Malaret, A. Lexicón de Fauna y Flora [1970]. Comisión permanente de la Asociación de Academias de la Lengua Española. Madrid) 


\section{Consumos y costes}

La construcción naval de las Indias tuvo una gran importancia, sobre todo en el siglo XVIII y en el Real Astillero de La Habana. De este último tenemos datos mas o menos exactos de los Estados de construcción que nos pueden dar por aproximaciones los consumos de madera que se produjeron. Durante el período que va desde 1715 a 1759 en el astillero de La Habana se construyeron 33 navíos de 50 cañones o más que pueden arrojar un consumo de maderas superior a los $100.000 \mathrm{~m}^{3}$ y su costo próximo a los cien millones de reales de vellón. En el Estado de construcción que abarca el período de 1724 a 1794 en el gran astillero antillano se construyeron 125 buques de diversos portes de los cuales 53 eran navíos de línea y 14 fragatas, que pueden suponer $190.000 \mathrm{~m}^{3}$ de madera en pie por un importe de 180 millones de reales. (Casals Costa, V. da que para la construcción de una fragata se utilizaban $14.000 \mathrm{~m}^{3}$ de madera en rollo, cifra que parece del todo excesiva).

Los costes de construcción individualizados fueron muy diferentes según el lugar de ubicación del bosque y del astillero, la cantidad y calidad de la mano de obra y la dificultad o facilidad de la extracción, y así en el astillero de Coatzacoalcos en 1734 la construcción del único navío que salió en sus dársenas, el «Nueva España», de 60 cañones, alcanzó la cifra astronómica de 4.969 .870 reales (34).

Las oscilación de los precios forestales, estudiados por Hamilton (35), pueden servir de referencia a un estudio más concienzudo de los caudales públicos gastados en la construcción naval de los astilleros de La Habana, Guayaquil, Veracruz, Coatzalcoalcos, Chiloé, La Tenaza, etc... y al otro lado del océano en el Real Astillero de Cavite. Pero ello nos llevaría a unas cifras frías que no darían una respuesta al gran esfuerzo constructivo que se realizó en los astilleros americanos y que permitió abastecer con el producto de sus bosques y el trabajo de sus gradas a la flota de las Indias que durante más de 300 años fue el nexo de unión entre la península y la gran colonia de América (36).

Pero no solo la industria naval fue la consumidora de las maderas de los bosques indianos; sino que los ingenios azucareros durante el siglo XVIII, en la Isla de Cuba, tenían unas exigencias de maderas y leña de 500 caballerías equivalente a 6.710 Has. Entrados en el siglo XIX estas cifras se duplicaron (37).

Los consumos de madera referidos a la construcción naval por los astilleros de la gran Antilla no deben de sorprender por su magnitud; el Plan 
de Fomento de la Marina del Reino de Francia de 1689 requirió una cantidad próxima a los $370.000 \mathrm{~m}^{3}$ de madera en pie, la gran mayoría de roble. Más tarde el Plan galo de 1786 necesitó de 11,3 millones de pies cúbicos que traducido a unidades métricas suponen un volumen de madera próximo a los $600.000 \mathrm{~m}^{3}$, cifra próxima a la producción total de los robledales de Francia por entonces (38).

\section{NOTAS}

(1) Cristobal Colón, Carta de Luis de Santangel de 15 de febrero. Referencias a la Is. Juana (Cuba). [...] Sierras y montañas altísimas, sin comparación de la isla de Tenerife, islas hermosísimas, de cual hechuras y todas andables y llenas de árboles de mil maneras y altos, y parecen que llegan al cielo; y tengo por dicho que jamás pierden la hoja y según lo pude comprender.que los vi tan verdes y tan hermosos como son por mayo en España y de ellos estaban floridos y de ellos con fruto y de ellos en otro término, según es su calidad. $Y$ cantaba el ruiseñor y otros pajarillos de mil maneras en el mes de noviembre por allí donde yo estaba. Hay palmeras de 6 o de 8 maneras, que es àdmiración verlas por la diformidad hermosa de ellas, más así como los otros árboles y frutos y hierbas. En ella hay pinares de maravilla y hay campiñas grandísimas y hay miel de muchas maneras de aves y frutos muy diversos. En la tierra hay muchas minas de metales y hay gente instimable número...

(2) Wirson, EDWARD (1989), Investigación y ciencia, noviembre. «La diversidad de la selva tropical ${ }^{1}$... más de la mitad de todas las especies de la Tierra viven en las selvas tropicales.húmedas.

... El record mundial lo estableció en 1988 ALWYN H. GeutRY del Jardín Botánico de Missouri, que identificó unas 300 especies de árboles en cada una de las parcelas de una hectárea cerca de Iquitos, Perú.

... la hecatombe de especies producida por la TALA e incendio de las pluriselvas tropicales. La selva se ha reducido ya a aproximadamente el $55 \%$ de su extensión original y sigue menguando a un ritmo que supera los $100.000 \mathrm{~km}^{2} /$ año. Esta cifra supone un $1 \%$ de su extensión total, más que la superficie de Suiza y Holanda juntas.

... Si se toma una cifra muy prudente de dos millones de especies confinadas en las selvas, la pérdida total que resulta de la desforestación podrá ser del orden de 4.000 a 6.000 especies año. Ritmo que es del orden de 10.000 veces superior a la tasa natural de extinción de base que existía antes de la aparición del hombre.

1 «Biodiversity». Wilson and Frances. M. Peter. National Academy Press 1988.

(3) Memorias de la sociedad económica de amigos del país (reedición de "Ruina de nuestros preciosos bosques y necesidad de reponerlos»), La Habana.:1843. (Reedición «Memoria de los bosques», 1797), La Habana. 1851.

(4) Las ordenanzas de Marina en América. En ultramar existía la misma administración forestal de Marina que en la península, aunque menos severa y más concentrảda en la explotación de madera. Como ejemplo, se puede mencionar la isla de Cuba, cuyo astillero en La Habana tenía un valor extraordinario para la Marina, que poseía la administración 
de los bosques que distaban hasta 220 kilómetros de la capital, a lo largo de la costa norte, en una franja de 33 kilómetros. A la población de La Habana se le concedieron 8 haciendas de bosques, donde se podía proveer de madera de construcción.

(5) Ordenanza provisional para el arreglo, aumento y conservación de los montes de Guayaquil. Reproducida por M. L. LaVIana Cuetos (1989) en Ciencia, Vida y Espacio en Iberoamérica. Madrid, CSIC. Vol. II, pp. 397-413.

En dicha ordenanza se reglamentan las cortas y la exportación de maderas, estableciéndose una guardería para los bosques y se dictan providencias para la repoblación forestal.

El gobierno colonial y el cabildo establecieron una pugna para controlar las explotaciones forestales en Guayaquil. (Ref. M.L. Laviana).

(6) Marrero Leví (1970): Geografía de Cuba. N. Y. Minerva Broks, p. 299.

(7) Rodrfguez Ferrer, MANuel (1876). Naturaleza y Civilización de la grandiosa isla de Cuba. Madrid. Imp. de J. Noguera, Vol. I, p. 686.

(8) Archivo de Simancas. Secretaria de Marina, legajo 552.

1720 En la clase de arsenales de este año, se halla copia del Despacho del Consejo de Indias expedido el 28 de junio de 1699 sobre la libertad de cortar maderas en La Habana a los fabricantes de naves.

1734 Se prohíbe la corta de madera a los montes de La Habana. Ello indica que las talas que se han hecho en los montes eran de mucha consideración.

1737 D. Josef Antonio Fallapiedra recibe permiso para construir un navío en la isla de Cuba, en cualquier lugar de su elección, a excepción de La Habana.

1738 Los baxeles de América Constante y América deben ser reparados en el Astillero de Cartagena. Para ello se dispone emplear el cedro macho para tamboretes y caoba.

1739 D. Lorenzo Montalvo pide palos de arboladura para 2 navíos en construcción en La Habana.

174014 de enero: llegan a Santander los barcos de América León y Castilla con cargas de plata y madera. Esta se llama Guayacán y es a saber del León 400 troncos de 25 a 45 pulgadas de lärgo y 4 a 11 pies de diámetro; del barco Castilla 338 troncos de 25 a 40 pies de largo y $41 / 2$ hasta 16 pies de diámetro.

1741 D. Francisco de Varas de Cádiz, solicita urgentemente madera de Indias a saber: cedro y caoba para los astilleros de Cádiz y El Ferrol.

1777 Se informa desde La Habana sobre géneros de material recibidos, entregados y consumidos en el astillero de este puerto, correspondiente al mes de septiembre de 1776. Se trata de considerables cantidades de madera entre otros: madera dura para navío, madera dura para fragata, madera dura para goleta y piragua, madera de cedro para navío, madera de cedro para fragata, madera de cedro para goleta, piragua, gangil y lancha; toras de caoba; toras y tirantes de cedro; tablonería de cedro, palos de pino de Nueva Orleans.

Archivo de Simancas. Secretaria de Marina, legajo 554.

1747 El gobernador de La Habana da Providencias para la conservación de los montes y construcción de baxeles en el Real Astillero de La Habana. 
Archivo de Simancas. Secretaría de Marina, legajo 575.

$1747 \mathrm{Al}$ gobernador y ministro del astillero de La Habana.

"Que no recorten árboles algunos para la construcción de baxeles que esta por asiento a cargo de la compañía, sino en los menguantes de las lunas de noviembre, diciembre, enero y febrero y que sean cedros machos y no hembras las que se corten".

Archivo de Simancas. Secretaría de Marina, legajo 567.

1775 Actas sobre montes de Indias.

1. Pleitos sobre competencia en montes de La Habana.

2. Talas de Madera para una Fábrica de Tabacos.

3. La Administración de Marina propone poner todos los montes bajo su tutela.

4. Decisión de conservar los montes de Guayaquil, pues allí hay un astillero, teniendo entendido el desorden que se procedía en los cortes y extracciones de los montes de Guayaquil.

5. Oficial de Marina, D. Félix Estrada, hace una visita en la isla de Cuba en los montes de la Hacienda, en la Bahía del Jaguar. Encuentra las siguientes clases de madera:

Cedros para navíos, cedros para fragatas, savinies, tavay, cahovay. En total: 43.180 árboles.

(9) Visitas de la Marina en Cuba. En las visitas a los montes realizadas por los subdelegados de la Marina se buscaban también los árboles adecuados para el transporte a los astilleros de España. Se calculaba su peso por codos cúbicos, y su calidad respecto a duración, etc., determinando para qué tipos de barco se podía usar la madera, la posición del bosque y las posibilidades de tala y transporte a la costa, etc. La visita de montes en la parte oriental de Cuba fue verificada por el capitán e ingeniero jefe De la Puente, entre 1790 y 1796. En los primeros dos años asignó 4.840 .969 codos cúbicos. Como prueba se talaron 20 troncos y se mandaron a España. Simultáneamente el ingeniero y alférez de Marina Lecoq hacía la visita de montes en la parte occidental de la isla, y con tal exactitud, que describía hasta el color y el grado de humedad del suelo, el terreno y el número de las especies de árboles existentes en cada bosque. Por talas de ensayo constaba que solamente la mitad de los árboles elegidos servían verdaderamente para la Marina, teniendo el resto más o menos grandes defectos.

Los oficiales de Marina en Cuba verificaban también el reconocimiento de montes para examinar las peticiones de rozas de los hacendistas. En el año 1794, por ejemplo, siete labradores solicitaron la destrucción de sus bosques. El capitán de fragata encargado de hacer el reconocimiento hizo constar que solamente en tres casos se podía dar la licencia. Es sorprendente esta decisión, pues en la península se permitían excesivamente las rozas de bosques, como lo demuestran las actas de Simancas.

BAUER, E. (1980). Los Montes de España en la historia. Mapa.

(10) ARANDA y ANTÓN, GASPAR DE (1991). «Reflexiones..Cuando los montes eran de la Marina». Rev. Historia Naval. n. ${ }^{\circ} 33$.

\section{La Selvicultura en la Marina}

De un análisis del criterio de máximö rendimiento de masas forestales, gestionadas en los montes y bosques de robles aprovechados por la Marina Real del siglo XVIII en tierras 
de realengo y de propios de los pueblos, se desprenden los siguientes parámetros que configuran el modelo:

- Estructura de la masa forestal: De forma irregular con todas las edades de los pies representadas en el rodal o en el cantón con todos los pisos y estratos de vegetación.

- Criterio de selección en la corta: De características tecnológicas, buscando en el árbol en pie la pieza o ligazón más conveniente para el ùso naval en razón al diseño del navío según su porte. De tipo dendromórfico pie a pie en una forma particular de entresaca no regularizada de corte atípico.

- Turno de la corta: Se busca la mayor lozanía en el árbol, a partir de la segunda centuria de su vida, aproximadamente a los 150 años. El mantener la masa arbórea una estructura irregular no está clara la noción de turno.

- Especie. De carácter monoespecífico por las excelentes características marineras de la madera de roble.

- Método de ordenación: Al no existir un criterio selvícola en la gestación del bosque, así como una metodología para la consecución de una renta al vuelo y al suelo manteniendo la persistencia del robledal; no se puede hablar de la obtención de un monte ordenado bajo la óptica de la planificación, por la Marina del siglo XVIII y por tanto no existe la tendencia a un monte normal según Judeich.

- Posibilidad: Al ser la selección de los árboles para madera independiente y ajena a la renta del bosque de roble en razón a los crecimientos anulares periódicos, así como, por falta de una desametría desarrollada y, por tanto, de inventarios de existencias de biomasa, en estructuras regulares no es posible determinar una posibilidad o renta ejecutiva.

- Gestión del bosque: No se encuentra en los aprovechamientos de los montes y bosques de la Jurisdicción de Marina una gestión selvícola, cosa a la vez común en toda la Europa del siglo XVIII.

- Trabajos culturales: Como trabajos selvícolas sólo se conocen la guía de árboles de tipo morfológico y las podas de formación.

- Apoyo a la generación: Se promovieron con tibieza campañas de siembras y plantíos más en razón de la escasez de maderas y leñas que por criterios estratégicos de conservación. Siempre las labores de restauración estuvieron por debajo del capital maderero extraído del bosque.

- El ecosistema robledal: Los montes y bosques de la cornisa cantábrica fueron tanto por su situación geográfica como por la calidad de sus maderas, los más gestionados por la Marina ilustrada. Las costas encaminadas a la extracción de pies de robles, eliminaron aquellas especies situadas en las más altas posiciones de las series regresivas de vegetación. La asociación vegetal climax se perdió la mayoría de las veces sin posibilidad de recuperación. Como consecuencia de todo ello el ecosistema primigenio desapareció, modificando la configuración de aquellos montes y bosques costeros.

Carballo y Sampayo, D. (1795). Elementos de Agricultura. Imp. Real. Versión española de D. Joseph María Calderón de la Barca. En el prólogo de la obra referenciada a Guarnizo:

- ... en el astillero de Guarnizo contenido en la misma bahía: se han construido navíos y fragatas de guerra, y se construyen frecuentemente bergantines y otros bu- 
ques de 300 toneladas para el comercio de América y de la península. Cerca de la Bahía está la fundición de cañones de la Cavada...

Preparación de los árboles para uso de la.industria naval:

Quando estén criados (los árboles) pueden trasplantarse al bosque: y se dexarán crecer derechos, con una sola guía para formar bigas, biguetas y maderos de todos los tamaños, ó se pueden podar a quince o veinte palmos de la tierra para formar troncos y ramas: que pueden dar toda suerte de madera útil para la Marina...

GAZTAÑEDA, ANTONIO (1736). Proporciones de las medidas más esenciales... para la fábrica de navios y Montes de Vizcaya. Madrid.

VILLAREAL DE BERRIZ, P. B. (1736). Máquinas hidráulicas de molinos y herrerías y gobierno de los árboles y Montes de Vizcaya. Madrid. Trata de innovaciones. tecnológicas para aprovechamientos hidráulicos. Parte de una obra es un tratado de selvicultura.

GoRDo J. et GIL, L. (1990). «Los bosques españoles y el catálogo de montes de utilidad pública». Rev. Ecología ICONA. Los dos primeros tercios del s. XIX se caracterizan por la destrucción del ya mermado patrimonio forestal, que había permitido ser una potencia naval en el s. XVIII y ganadera en los anteriores, siempre a costa de los bosques.

JovellaNos y RAMíREZ, GASPAR DE (1795). Informe de la Sociedad Económica de Madrid al Real Supremo Consejo de Castilla en el expediente de la ley Agraria. «El bosque no necesita cuidados para su repoblación, pues no hay cosa más constante que la reproducción natural de los montes por sí mismos».

Pérez Quintero, Miguel Ignacio (1798) Madrid. Hace referencia a los plantíos y cortas de madera para la construcción de bajeles. Más tarde trata de las condiciones que deben reunir los delineadores y guardas de montes en las provincias de Marina.

CORNIDE, JosÉ (1785). Carta dirigida por D. José Cornide vecino de-La Coruña a un amigo de Madrid que le consultó sobre el método de adelantar las Dehesas-Reales en Galicia. M. 1785.

Sobre la restauración por etapas:

... De uno y otro tengo experiencia en una hacienda cerca de la costa en la Ría de Sada, a donde se puede logar castaños y robles hasta que los pinos les hicieron un ventajoso abrigo y lo mismo he visto cerca de puerto de Malpica...

BOWLES, GuILLERMo (1775). Introducción a la historia natural y Geografía física de España. Imprenta Real.

(11) SAGRA RAMÓN DE (1831). Historia Económica-Política y Estadística de la Isla de Cuba. La Habana. «En estas "tumbas" se sacrifican todos los árboles y caen bajo el hacha exterminadora robustas acacias y caobas, corpulentos cedros y sabicúes, antiquísimos chicharrones y guayacanes, y otros árboles de maderas preciosísimas que el fuego consume en pocos días. Los cortes de leña, ya para los ingenios, ya para hacer carbón, sacrifican también árboles de mayor precio, que ni se reponen ni es posible conseguirlo en cuatro generaciones. De resultas de esta tala asoladora y del sistema de imprevisión que la dirige, se ven transformadas en llanuras estériles y abrasadas terrenos antes pingües y frondosos, se han abandonado fincas valiosas por falta de combustible, se ha acrecentado el coste de los materiales para el establecimiento de las nuevas, y sucesivamente se verán subir la temperatura y escasear las lluvias en las inmediaciones de las ciudades; desaparecerán los benéficos y abundantes rocíos, que en la época de la seca suplen a la falta de aguas, en las comarcas de grandes arboledas, condenando al exterminio las plantas y los animales en los meses de noviembre a marzo, y en: los calurosos, no se percibirá el soplo vivificador de los 
bosques ni el olor balsámico de las flores silvestres. En fin, donde se aniquilen los árboles, una escena de soledad y muerte se sustituirá el risueño espectáculo de los afanes de la industria bien dirigida".

Los Cortes del Rey antes mencionados habían sido reglamentados por las leyes 13 y 15, título 17, del libro 4 de la Recopilación de Indias, dados en los años 1622 y 1625, que regulaban las cortas de caobas, cedros y robles, permitidas sólo "para el servicio real o fábrica de navíos»; a lo largo del siglo XVIII diversos decretos reafirmarían el monopolio de la Marina sobre amplias zonas de los bosques de la isla. Sin embargo, ya en 1779 hubo que constituir en La Habana una Junta de Maderas que intentará conciliar en conflictos surgidos entre la Marina y los hacendados; en 1789 se estableció un reglamento que estipulaba el modo de proceder en los cortes y en 1796 una Real Orden reafirmaba los derechos exclusivos de la Corona en toda la franja costera de la isla. Esta Real Orden encontró la abierta oposición de los hacendados, a resultas de los cual

«El Consulado de La Habana representó en 22 y 31 de mayo de 1798, sobre los perjuicios que tales providencias causaban a la agricultura y a los derechos de propiedad, pues los dueños de los terrenos no podían disponer de ellos, establecer los cultivos, ni impedir que cualquiera cortase madera de sus bosques.»

Tal representación marcó el inicio de la privatización total de los bosques cubanos. La Corona pidió diversos informes, entre ellos a los ex-gobernadores Conde de Espeleta y Luis de las Casas. Este último, impulsor de la creación de la Sociedad Económica de La Habana, se expresó en términos inequívocamente liberales, ligando el progreso de las «sociedades civilizadas». En cuanto a los bosques, su visión era abiertamente optimista:

"En el actual sistema - dirá- en que sólo puede haber el interés de talar y no de renovar el monte talado, sería preciso que pasasen siglos antes de que se agotasen los bosques más conocidos de la isla.".

Por Real Orden de 14 de febrero de 1800, se estableció una Junta "que acordase las reglas que podía adoptarse para satisfacer las necesidades de la Marina, sin perjuicio de los particulares", la cual concluyó que los montes son parte de las tierras y que por tanto

«Las Leyes recopiladas como otras muchas determinaciones soberanas, no dejan la menor duda de que los poseedores de las tierras, con justo título son dueños de ellas, sin reserva alguna en favor de la Corona."

Las Cortes de 1812 abolieron toda la legislación de montes anterior y aunque Fernando VII restituyó ésta en parte, en lo que respecta a Cuba y Real Cédula de Montes y Plantíos, de 30. de agosto de 1815, consagró definitivamente la propiedad privada sobre los bosques. Como señala Marrero, tal Real Cédula posibilitó la expansión sin trabas legales de la caña y la despreocupación casi total respecto a las funciones sociales de los montes.

Aunque el triunfo de las ideas del liberalismo económico acarreó la progresiva destrucción del bosque cubano durante el ochocientos, en algunos sectores ilustrados de la isla se habían manifestado en fechas tempranas diversas opiniones sobre los peligros que comportaba el desmonte indiscriminado. Los dos trabajos probablemente más importantes fueron los debidos al Conde de Mopox y Jaruco y José Ricardo O'Farril. Ambos señalan los peligros que comporta la desforestación, resultado "del uso común de lo que ha producido espontáneamente la Naturaleza» (Mopox) y del hecho que el «estado poco adelantado de nuestra cultura suple con la extensión del terreno la falta de un buen cultivo" ( $O$ 'Farril). Este último se referirá explícitamente a las funciones sociales del monte al indicar que an- 
tes de pensar en enriquecimiento «se trata de vivir, y según las relaciones que tienen las cosas con nuestra existencia, así graduamos su preferencia». Y continuará: .

"Asentado esto, y que no puede haber quien niegue las relaciones que tienen los montes con nuestra vida y sus comodidades, ¿cómo vivimos tan poco solícitos con su conservación y aumento? ¿Cómo no prevenimos las consecuencias que pueden sobrevenir a esta población de su exterminio? ¿Acaso será por tener a la vista pueblos numerosos y ricos que subsisten sin ellos? ¿No conocemos que estos mismos pueblos acreditan su importancia, viviendo en cierto modo de la dependencia de aquellos que lo poseen? $[\ldots]$ ”

O'Farril propondrá una serie de medidas para superar tal estado de cosas, entre ellas la prohibición de quema de montes, el destinar en todos los pueblos terrenos para la cría de árboles y premios a los vecinos que se distingan en el cultivo arbóreo. Asimismo, propone que la Sociedad Económica establezca escuelas de agricultura en todas las cabezas de partido.

Poca debió ser la repercusión de estos escritos en su momento. Medio siglo después, a mediados del XIX, cuando la desforestación de la isla había alcanzado características amenazadoras incluso para la propia industria del azúcar, la Sociedad Económica los desempolvará y los publicará junto con otros trabajos más recientes. Ya a principios del siglo XIX el técnico azucarero José Ignacio Echegoyen había señalado: «Espanta la necesidad de leña de un ingenio. ¿Y dónde hay montes que basten?" La polémica entablada entre hacendados y marinos en torno a la libre disposición de los montes por los propietarios fue un debate, tal como señala Ramón de la Sagra, en el que nunca se trató sobre la explotación racional del bosque. "La cuestión discutida - señala éste- se reducía a saber quién, la marina o los particulares, tenía el derecho de talar y destruir la vegetación forestal», considerada por todos como extremadamente abundante. Abundancia que con el tiempo trocó en escasez: en el momento de la llegada de Colón se calcula que los bosques de Cuba ocupaban el 60\% de su territorio; en 1852 ocupaban el $40 \%$ y en 1923 representaba solamente el $16 \%$ de la superficie de la isla. El azúcar se había comido el bosque».

(12) Jorge JuAn y ANTONIO de Ulloa (1826). Noticias secretas de América. Londres: Imp. de R. Taylor.

(13) El Palo de Campeche. Carlos III concedió a los ingleses licencia de corte del palo de campeche. Felipe $\mathrm{V}$ suprimió esa autorización, aunque los ingleses siguieron cortándolo de forma clandestina con la colaboración de los indios miskitos a través de las costas hondureñas.

Años más tarde, sobre el 1752, reinando Fernando VI, las intrigas del embajador inglés ante la Corona Española Benjamin Keene hicieron que se desbaratara el plan del marqués de la Ensenada de fomento de la Marina Española, impidiendo la fortificación de esa zona de América Central, quedando casi indefinidamente una parte de tan alto valor estratégico en poder de los ingleses.

(14) Astillero de La Habana. Füsrstenberg: Formen der Waldnuntzung in spanischen Nord-und Mittelamerika.

«Las naves construidas en La Habana tenían fama de extraordinaria calidad. Entre 1734 y 1781 se construyeron allí nada menos que 67-grandes navíos de guerra. Cuando el Ministro Ensenada planeó dotar a la Armada con 15 nuevas unidades, los 10 barcos de mayor tonelaje fueron construidos en La Habana y únicamente en El Ferrol» las 5 embarcaciones menores. 
(15) Aranda y Antón, GaSpar de (1990). Los bosques flotantes. Col. Técnica Icona. Madrid 1990.

Pág. 78. La Habana. Ya en 1717 existía el proyecto de creación de un gran astillero en la Gran Antilla para construir, apostar la flota, reparar y carenar buques. J. Campillo creó un gran astillero en 1725. Siguiendo el método Gaztañeda se construyeron muchos buques entre 1726-1739 mediante asientos en la Compañía de La Habana, continuando la construcción durante los años 17411749. La actividad siguió hasta 1750.

Real Astillero del Sitio de la Tenaza. Cuba.

Creado en 1735, y remodelado en 1739 según el Plan de ampliación y modernización de la Armada promovido por el Marqués de la Ensenada.

Se crea un asiento con la Marina y la Real Compañía de Comercio de S. Cristóbal de La Habana por lo que el período que va de 1741-1749 se contrata la fabricación de 10 navíos de línea.

Se abastecía de maderas de la zona de Chihuaua, Matanzas, Camariova, Sagua y Bahía Honda.

Entre 1769-1794 se botaron 7 navíos de la serie de 12 de 70 cañones.

(16) Astillero de Guayaquil. La construcción en 1752 del navío S. José el Peruano resultó un completo fracaso.

Carlos III decidió en el año 1768 relanzar el astillero: para ello en el año 1783 se solicitó al gobernador de la región que recogiera muestras de distintos géneros de maderas que se producían en dicha jurisdicción.

En 1790 el navío Santiago el Fuerte partía con 24 trozos de cada una de las maderas seleccionadas: guayacán, negra, caña, fístola, tinto, algarrobo, mangle caballero, mangle colorado, canelo, matasarna, cacol, coquito, amarillo y colorado.

En las inmediaciones de Guayaquil se llegaron a contar 30.000 árboles de edad y tamaño capaces para servir para navíos de $\mathbf{7 0}$ cañones. Para embarcaciones mayores se seleccionaron las maderas de roble, canelo, guachapeli, moral, cañafístola, amarillo, colorado y bálsamo.

(17) Clayton, L. A. (1798): Los Astilleros del Guayaquil colonial.

(18) - Astillero de Realejo. Carta fechada en Lima el 12 de agosto de 1769, el capitán Orejuela afirma que las maderas de Realejo son las que tienen más duración de todas las Indias.

Archivo General de Simancas. Secretaría de Marina, leg. 349.

Proyecto para construir bajeles de S.M. en el Puerto de Realejo en el golfo de Fonseca.

Ver. Construcción de baxeles. Ferrol, Cartagena, Havana y propuesta para emprenderla en la Mar del Sur. Lima. 1772.

Archivo General de Simancas. Secretaría de Marina, leg. 349.

Relación de maderas útiles para construcción de bajeles y servicio de casas que produce el Puerto de Realejo y se hayan en abundancia en sus inmediaciones.

M. S. 126, ff. 228-231 y 253-255. Museo Naval. Madrid.

(19) Bethancourt. Massieu, Antonio (1958). El Real Astillero de Coatzalcoalcos (17201735).

(20) Bethancourt Massieu, Antonio, op. cit.

(21) Maderas para la Marina. Sta. María de Chimialapa: se hicieron talas de árboles para arboladuras.

Asclepio-Vol. XLV-1-1993 
(ver) Bethancourt Massieu, Antonio (1960). «Arboladuras de St ${ }^{a}$ María de ChimilapaTehuantepec en las construcciones indianas». Rev. de Indias, 79.

(22) ARANDA y ANTÓN, GaSPAR de (1990), op. cit.

... No obstante los astilleros de La Habana fueron los más importantes del imperio español durante el período comprendido entre 1730 y 1749 con 33 navíos. Otros autores cifran en el período de 1724 a 1794 la construcción de 125 buques de guerra entre ellos 14 fragatas y 53 navíos de 3 puentes: (ver Rodríguez FERRER, MANUEL (1876). Naturaleza y Civilización de la Grandiosa Isla de Cuba).

(23) Juan Santacilia, Jorge y otros. Durante los siglos XVI y XVII gran parte de las embarcaciones fueron construidas en los astilleros de las Indias.

Un ejemplo de ello es que de los 239 buques utilizados en los viajes de las Flotas de Indias en el período comprendido entre 1669 y 1700, 47 embarcaciones, es decir, una quinta parte, fueron criollos. Por entonces los astilleros y arsenales de La Habana, Guayaquil y Cavite eran famosos (ver. BETHANCOUR).

Palacio Atard, V. et al. (1989). España y el Mar en el siglo de Carlos III. Marinvest. Madrid. Archivo del Viso. Arsenales, varios 1785, leg. 8.

(24) Juan, Jorge y UlloA, Antonio de (1826). Noticias secretas de América. Ed. de David Barry. Londres.

(25) JUAN, JoRge y Ulloa ANTONIO DE, op. cit..

(26) Enemigos de la madera de Indias. Ms. 126, F. 247. Museo Naval. Madrid.

... Además de la «broma", también frecuente en Panamá, así como en otros lugares de América, el «comejen» era el principal enemigo de las maderas panameñas. Hasta tal punto abundan allí estos insectos de la familia de los termitidos, que así se llama hoy día una región del istmo.

ARANDA Y ANTÓN, GASPAR DE (1991). «La broma, azote de navíos», Vida silvestre, n. ${ }^{\circ} 69.1$ er. Semestre. 1991.

... En los galeones que desde el siglo XVI efectuaban la carrera de Indias, la arribada de estos a los mares y puertos caribeños les acarreaban un aumento de los daños por estos moluscos (Teredos), en razón a que las maderas europeas que constituían el armazón y los forros de las embarcaciones eran presa fácil de la «broma"...

... No ocurre lo mismo en las maderas tropicales, en general más resistentes a estos moluscos xilófagos; como ejemplo tenemos el capá o cordia, el guayacá, la shorea y la discorynia y, como no, la caoba cubana -Swietenia mahogani- De estas ventajas se aprovecharon nuestros arquitectos navales, haciendo florecer en el siglo XVIII astilleros como el de La Habana y el de Coatzalcoalcos; del primero salió el navío Santísima Trinidad de más de 3.700 toneladas de registro y de cuatro puentes, único buque de esas características que ha surcado los mares.

Tinajero, Bernardo (1712). Duración de los navíos. «... los más es que si se fabrica en Vizcaya duran, que se duda, diez años, el de Indias pasará de treinta, ... la fortaleza y seguridad de los navíos fabricados en Indias, ..., no se encontrará en el mundo igual...».

UzTARIZ, en 1724, hace igual observación.

(27) Maderas de Cuba a la península. La madera se transportaba en barcos especiales desde las Indias a España. Hacia finales del siglo XVIII existía el plan de trasladar anualmente cerca de 70.000 codos cúbicos de madera a Cuba a Cádiz y El Ferrol, y la Junta de Marina de Cartagena de las Indias recibió, en 1790, el aviso de mandar cada año 60.000 codos cúbicos a los astilleros españoles. 
La Marina estableció, por primera vez en España, una administración forestal, ocupándose del aprovechamiento de la madera, tanto en la península como en ultramar.

De las posesiones de ultramar se enviaban - como ya mencionamos- palos de tinte (Caesalpinia echinata y otros) a la península, el llamado "palo brasil». Brasilieros se llamaba a los comerciantes de esta madera. En 1620 llegó a Sevilla la enorme cantidad de 107.688 quintales de palo brasil, es decir, 5.384 toneladas, con un valor de 14.838 .100 maravedíes. Eran considerables las cantidades de esta madera que se exportaban a Gran Bretaña, siendo este comercio, en parte, clandestino o semi-legal.

Queda por mencionar la madera noble para muebles y adornos que se mandaba en cierta cantidad a España durante el siglo XVIII; no era grande, pues las dos especies más importantes, caoba y cedrela, estaban reservadas para usos de la Marina (leyes de Indias, 13, título 17, libro 4), hasta que en 1789 el rey permitió el comercio con estas especies, siempre que la Junta de Montes de Cuba hubiese declarado que no era necesaria para los astilleros ni la construcción de edificios. Un caso especial lo constituyó el transporte de caoba cubana para la instalación del Palacio Real en Madrid entre los años 1739 y 1793, que se verificó con barcos de la Armada.

BAUER, E. (1988). Los Montes de España en la Historia, MAPA

(28) JUAN SANTACILIA, JoRge (1752). Reglamento de las maderas necesarias para la fábrica de la inglesa de un navio de 68 cañones, una fragata de 52 y otra de 44. Junta de constructores. Los buques construidos por este sistema eran muy sólidos gracias a un estudio científico de los escantillones, siendo un ejemplo del navío "Guerrero" de 74 c. construido en 1755 y que fue dado de baja en 1844.

Archivo General de Indias. Marina. Legs. 318 y 324. «Nuevo método de construcción español..."

(29) ARANda y ANTón, Gaspar de (1991). «Reflexiones. Cuando los montes eran de la Marina". R. Historia Naval n. ${ }^{\circ}$ 33. Maderas de roble empleadas en un navío. Partimos de datos de Juan Ruiz de la Torre y de Gervasio Artiñano y Galdácano: El primero nos dice que para la construcción de un navío se precisan 2.000 árboles de roble grandes en pie. El dato lo toma Ezequiel González Vázquez y cual lo recibe de José Jordana y Morena y de Eugenio Plá y Ravé, insignes ingenieros de montes del siglo XIX autores de trabajos sobre maderas para la construcción civil y naval.

Basándanos en las Tablas de Producción de robles de Jesús Ugarte Laiseca podemos establecer que el cubicaje medio de un roble de 150 años puede estar alrededor de los $2 \mathrm{~m}^{3}$.

Operando se obtiene que la cantidad de madera de roble necesaria para la construcción de un navío de medio porte en el siglo XVIII está alrededor de $4: 000 \mathrm{~m}^{3}$ de madera en pie.

Esta cifra en principio, y sólo para madera de roble parece exagerada, y está más en consonancia como cantidad total de madera, que en un navío de 70 cañones de diseño Gaztañeda se puede estimar en algo más de $\mathbf{2 0 . 0 0 0}$ codos cúbicos que suponen aproximạdamente los $4.000 \mathrm{~m}^{3}$ antes mencionados.

De Artiñano tenemos dos referencias, la primera es la cantidad de madera de roble necesaria para la construcción de un navío de 70 cañones que cifra en unos 10.000 codos cúbicos de madera labrada. Haciendo la correspondiente conversión a unidades métricas resultan casi $2.000 \mathrm{~m}^{3}$ de madera de roble labrada. La estimación de madera en rollo y en pie a partir de la madera labrada es difícil de determinar, tanto por la forma en que se realizaban las extracciones en el monte tanto en el apeo como en el desembosque. Además, el sis- 
tema dendromórfico ad hoc para la Marina ocasionaba elevadas pérdidas en residuos del producto. En base a valores obtenidos de tablas de reconversión se puede estimar la relación madera labrada a madera en pie de 0,65 .

Aplicando el citado coeficiente resultan unos $3.000 \mathrm{~m}^{3}$ de madera de roble en pie para la construcción de un navío de tres puentes, que consume en su construcción algo más de 180.000 pies cúbicos de madera. Como la madera de roble es aproximadamente el $54 \%$ de la madera total empleada según se deduce de los estados de construcción de navíos en el siglo XVIII podemos estimar en algo más de $1.800 \mathrm{~m}^{3}$ la cantidad de madera de roble necesaria ya labrada, que pasada a madera en pie se cifra también en casi $3.000 \mathrm{~m}^{3}$.

Por tanto todas las fuentes nos conducen a una cifra media próxima a los $3.000 \mathrm{~m}^{3} \mathrm{pa}$ ra navío de porte medio.

Hay que hacer la consideración de la variabilidad del consumo de madera según porte y diseño de arquitectura naval.

ARTIAÑo. GERVASIO DE (1720): La arquitectura naval española. Haciendo referencia a Vigodet muestra la situación de la armada española frente a la inglesa sobre el año 1751.

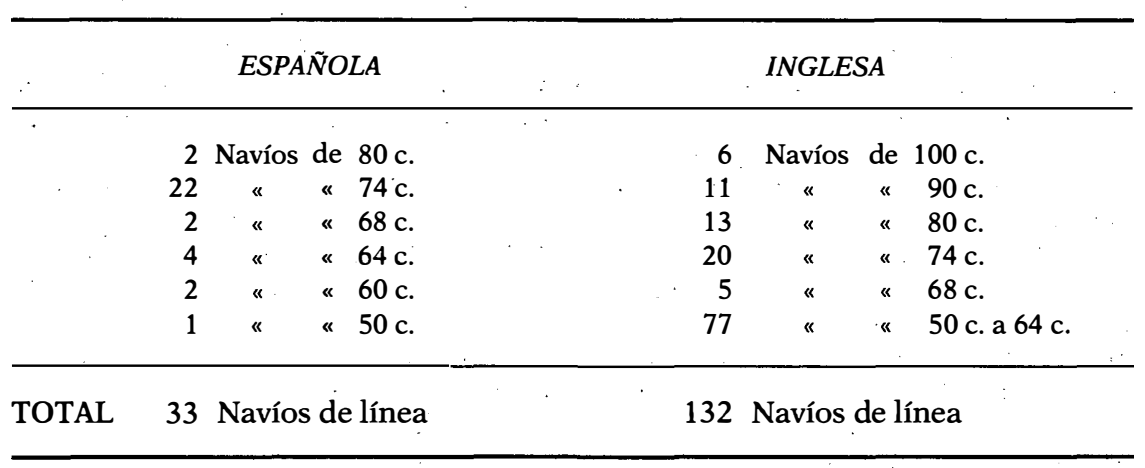

En cuanto a consumos de madera:

Un navío de 3 puentes consume en su construcción 184.707 pies cúbicos de madera que importan sobre $2.914523 \mathrm{r}$.

Arquitectura naval

Referente al plan de Jorge Juan de crear un diseño copiado del inglés.

Los jefes constructores ingleses fueron Rooth en El Ferrol, Howel en Guarnizo, Bryant en Cartagena y Mullan en La Habana.

AUTRÁN, CIPRIANo (1742). Método, regla y proporciones para la construcción de bajeles.

RUIZ DE LA TORRE, J. (1990). «Distribución y características de las masas forestales españolas». Rev. Ecología. Icona.

La proximidad a las costas y vías naturales de comunicación actúa en contra de la conservación de las vegetaciones terrestres.

La política naval afectó sobre todo a los montes de roble agotados en muchos casos, y a los mejores pinares, conservados gracias a sus ordenaciones. La producción de fibras, 
muchas de ellas de uso en la industria naval, habrá contribuido a fijar paisajes tan entendidos de antiguo como el atochar y el arbaldinal.

GonZÁlez Vázouez, E. (1948). Selvicultura. Madrid. Respecto a las cortas rasas: En las ordenanzas austriacas de 1786 ya se reconocían las cortas a hecho, seguido de repoblación, como un método general de regeneración de montes. En Alemania E. Cota en 1811 sistematizó las cortas rasas progresivas con reproducción deseminatoria lateral (cortas a hecho por fajas). En general fue en siglo XVIII cuando en Europa se practicaron las cortes rasas seguidas de repoblación. Esta práctica proliferó en Francia con masas de robles así como en Checoslovaquia y Suiza.

UsARTE LAISECA, Jesús. Tablas de producción.

Valores modulares medios del Q. Petreae

\begin{tabular}{rccc}
\hline$H$ & $O$ & $V$ & $C m$ \\
\hline 5 & 15 & 0,080 & \\
8 & 20 & 0,110 & 0,44 \\
12 & 30 & 0,320 & \\
15 & 40 & 0,730 & \\
18 & 50 & 1,340 & \\
21 & 60 & 2,150 & \\
25 & 70 & 3,160 & 0,33 \\
\hline
\end{tabular}

\section{LEYENDA}

$\mathrm{H}=$ Altura del árbol (en metros)

$\mathrm{O}=$ Diámetro normal del árbol a 1,30 (en $\mathrm{cm}$.)

$\mathrm{V}=$ Volumen del árbol en $\mathrm{m}^{3}$

$\mathrm{Cm}=$ Coeficiente mórfico.

(30) Noticia de las maderas que criadas en las inmediaciones de Guayaquil, consumen en la fabrica de casas y construcción de embarcaciones hasta de 900 toneladas. Ms. 126, ff. 231-235 v. Museo Naval, Madrid.

Noticias que se desean sobre las maderas y construcción en Guayaquil, por Francisco Ventura de Garaicoa (1790). Ms. 120, ff. 333-337 v. Museo Naval, Madrid.

Noticias relativas a la provincia y ciudad de Panamá (1790). Ms. 339, ff. 27-36. Museo Naval, Madrid.

Colección de las maderas de calidad que se encuentran en la provincia de Darien del Sur, por Fernando Murillo (1789). Cartagena de Indias. Museo Naval Ms. 126, ff. 244-248, Madrid.

Islas de Trinidad, Costa de Paría y Río Orinoco. Evaluación de la riqueza forestal.

1773. Gerónimo Franco. Alférez de Navío. 
1786: José Baulí, maestro de construcción de baxeles. $1^{\mathrm{a}}$ exp.

Maderas de: cedro, roble, pardillo, puy, aceite, cazapa, laurel, mangles y aura para quillas, sobrequillas, codastes y timones.

- Relación de las maderas que da Luis Nee, Botánico de S. M. en la expedición alrededor del mundo, que he observado en las diversas provincias que hemos recorrido desde el año 1789 hasta el de 1794 que duró nuestra expedición. Ms. 2296, ff. 279-302. Museo Naval. Madrid (con motivo de la expedición de Malaespina).

Noticias de las maderas que produce el puerto de Chiloé y sus cercanías para el servicio de los baxeles hasta el porte de 700 toneladas. Ms. 126, ff. 239-241 v. Museo Naval, Madrid.

Maderas de construcción, de fábricas y muebles en los puertos siguientes: Chiloé, Concepción, Valparaíso, Coquimbo, Guayaquil, Darien del Sur, Panamá, Realejo, Monterrey, Nutka, Mulgrave y otras varias noticias sobre maderas y navegación de ríos. Ms. 126. Museo Naval, Madrid.

(31) Maderas de Indias. Era normal que en la península ciertas piezas del buque (motonería, timón) se construyeran con caoba, sabicú o guayacán, por no hablar de su utilización masiva en edificaciones y mobiliario de lujo, caso del Palacio Real.

La extracción masiva de madera para la construcción de navíos y otras embarcaciones se hace en las Indias principalmente en las áreas caribeñas y antillanas: Cumaná, Trinidad, Cartagena y Cuba. Merino, J. P. (1981), La Armada Española en el S. XVIII, Madrid. (ver informe de F. GAUTIER, 1772).

(32) En Valparaíso se conocían las maderas de nogal, ciprés, canelo, roble, bellota y laurel. En Coquimbo sauce y algarrobo. Ver Noticias muy amplias sobre Coquimbo y Juan Fernández proporcionadas a la expedición en este puerto. Ms. 309, ff. 212-217.1. Archivo Museo Naval, Madrid 1790.

Respecto a la madera de Guachapeli (Guayaquil) se decía: «de color rojo y muy pesado. Su madera es la mejor para toda pieza de vuelta. En los fondos se puede decir incorruptible y donde no está siempre en el agua dura 30 ó 40 años.

La cañafístola era empleada para construir quillas, rodas, durmientes y codastes; el canelo y amarillo para los baos que sostienen las cubiertas del buque; el roble y mejor el que llaman mulato para tablazón, fondos y cubiertas. El palo-manía bueno para arboladuras.»

(33) En Acapulco (Nueva España) se obtenían de sus pinares la brea necesaria para el calafateado de las embarcaciones. En San Blas se hicieron descripciones del cedro, manglé y guayacán para embarcaciones. Ver Relación de las maderas que hay en el distrito de San Blas con especificación de sus dimensiones y virtudes. British Library add. 17622, ff. 1334136.

(34) Bethancourt, A. «El Real Astillero de Coatzalcoalcos».

Costos de producción. Astillero de Coatzalcoalcos, 1734.

El único navío construido en este astillero fue el «Nueva España» de 60 cañones que alcanzó la cifra astronómica de 4.969 .830 reales.

(35) Hamilton, E. J. (1988). Precio de los productos forestales en Castilla la Nueva en el período comprendido entre 1700 y 1800 .

En el período de 1700 a 1750 el coste del carbón vegetal y la leña estuvo por debajo su aumento respecto a los alimentos, especias y productos textiles. En el período comprendido entre 1750 y 1800 los precios se dispararon incluso por encima de otros bienes de consumo. 
En el segundo período la escasez de leñas y carbones fue manifiesta, fruto de una progresiva desforestación.

El problema de carencia de combustibles en Castilla fue extrapolable a otras regiones peninsulares y así en Cataluña el precio de la leña y del carbón subió casi un 300\% entre 1740 y final del siglo XVIII. (ver P. VILLAR [1975], Catalunya dins L'Espanya moderna, Barcelona, Ed. AP, vol. III, p. 235).

En Vascongadas los precios de las leñas para ferrerías y consumo doméstico aumentaron más que el cereal durante el siglo XVIII (ver. L. M. Bilbao y E. Fernández de Pinedo. "Auge y crisis de la siderometalurgia tradicional en el País Vasco: 1700-1850", también en P. TEDDE Ed. [1982]. La Economía Española al final del Antiguo Régimen II. Manufacturas, Madrid. Alianza Universidad, p. 172).

\section{PRECIO DE LOS PRODUCTOS FORESTALES}

Castilla la Nueva (1700-1800)

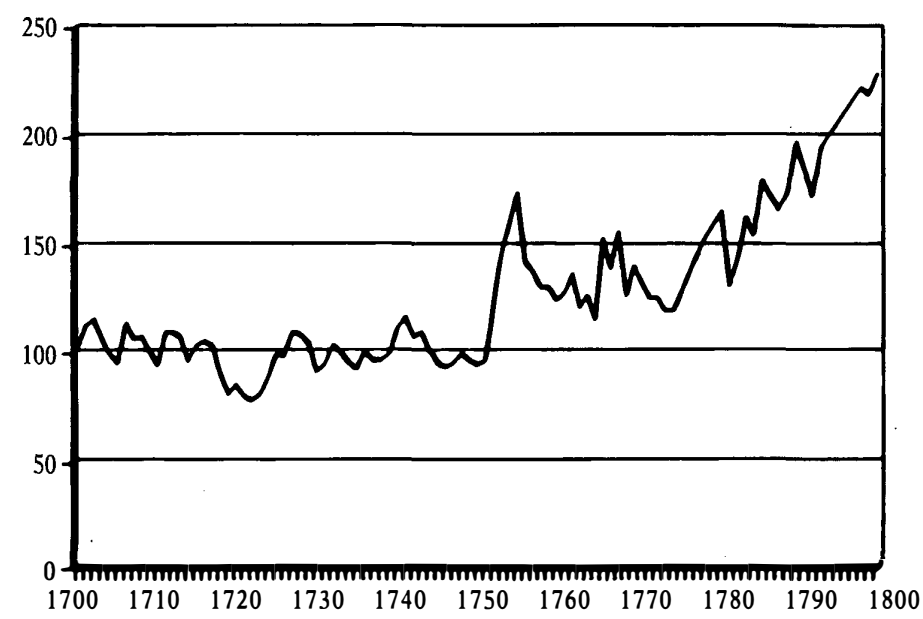

(36) Astillero de La Habana

Construcción

\begin{tabular}{cccc}
\hline Periodo & Total & Navios & Fragatas \\
\hline $1724-1794$ & 125 & 53 & 14
\end{tabular}


(37) Consumo de madera por los ingenios azucareros:

Siglo XVIII. Consumo anual de maderas y leñas $\longrightarrow 500$ caballerías equivalentes a 6.710 Has. (?)

En 1819 se duplicó la cifra anterior

(Fuente. Moreno Fraginals, ManUel [1978] El ingenio, complejo económico social cubano del azúcar, La Habana).

(38) Aranda y Antón, Gaspar de (1992). «La Política forestal en la Francia de "L'Ancien Regime" ". Revista Forestal Española, n. ${ }^{\circ}$, enero, pp. 20-27. 